\section{$\$$ Research Square}

\title{
Empagliflozin Restores Cardiac Metabolic Flexibility in Diet-induced Obese C57BL6/J Mice
}

\section{Bingxian Xie}

University of Pittsburgh School of Medicine

\section{Wesley Ramirez}

University of Pittsburgh School of Medicine

Amanda M. Mills

University of Pittsburgh School of Medicine

\section{Brydie R. Huckestein}

University of Pittsburgh School of Medicine

\section{Moira Anderson}

University of Pittsburgh School of Medicine

\section{Martha M. Pangburn}

University of Pittsburgh School of Medicine

\section{Eric Y. Lang}

University of Pittsburgh School of Medicine

\section{Steven J. Mullet}

University of Pittsburgh School of Medicine

Byron W. Chuan

University of Pittsburgh School of Medicine

Lanping Guo

University of Pittsburgh School of Medicine

Ian Sipula

University of Pittsburgh School of Medicine

Christopher P. O'Donnell

University of Pittsburgh School of Medicine

\section{Stacy G. Wendell}

University of Pittsburgh School of Medicine

\section{lain Scott}

University of Pittsburgh School of Medicine

Michael Jurczak ( $\sim$ jurczakm@pitt.edu )

University of Pittsburgh School of Medicine https://orcid.org/0000-0002-6335-6915 
Keywords: Metabolic flexibility, SGLT2, diabetic cardiomyopathy, heart failure, empagliflozin

Posted Date: September 28th, 2021

DOI: https://doi.org/10.21203/rs.3.rs-917468/v1

License: (c) (1) This work is licensed under a Creative Commons Attribution 4.0 International License. Read Full License 


\section{Abstract}

\section{Background}

Sodium-glucose co-transporter type 2 (SGLT2) inhibitor therapy to treat type 2 diabetes unexpectedly reduced all-cause mortality and hospitalization due to heart failure in several large-scale clinical trials, and has since been shown to produce similar cardiovascular disease-protective effects in patients without diabetes. How SGLT2 inhibitor therapy improves cardiovascular disease outcomes remains incompletely understood. Metabolic flexibility refers to the ability of a cell or organ to adjust its use of metabolic substrates, such as glucose or fatty acids, in response to physiological or pathophysiological conditions, and is a feature of a healthy heart that may be lost during diabetic cardiomyopathy and in the failing heart. While several studies have addressed metabolic changes in hearts in response to SGLT2 inhibitor therapy, none have specifically assessed metabolic flexibility in an in vivo system. We therefore undertook the described studies to determine the effects of SGLT2 inhibitor therapy on cardiac metabolic flexibility in vivo in obese, insulin resistant mice.

\section{Methods}

Diet-induced obese mice were treated with the SGLT2 inhibitor empagliflozin (EMPA; $10 \mathrm{mg} / \mathrm{kg} / \mathrm{d}$ ) for four weeks prior to study and compared with untreated obese and lean controls. We assessed changes in body weight and composition, plasma metabolites in response to fasting/re-feeding, cardiac hypertrophy by echocardiography, the response to ischemic stress following coronary artery ligation, as well as cardiac-specific rates of relative glucose and fatty acid utilization using a $\left[\mathrm{U}^{13} \mathrm{C}\right]$-glucose infusion during fasting and hyperinsulinemic euglycemic clamp.

\section{Results}

EMPA-treated mice presented with reduced cardiac hypertrophy and protection from ischemic stress compared with obese controls. In the fasted state, relative rates of cardiac glucose and fatty acid utilization were similar in control and EMPA-treated mice. During the hyperinsulinemic euglycemic clamp, rates of cardiac glucose utilization and metabolic flexibility were reduced in obese compared with lean mice, and EMPA-treatment partially restored both features.

\section{Conclusions}

SGLT2 inhibitor therapy restored cardiac metabolic flexibility in obese, insulin resistant mice, and was associated with reduced cardiac hypertrophy and protection from ischemia. These observations suggest that the cardiovascular disease-protective effects of SGLT2 inhibitors may in part be explained by beneficial effects on cardiac metabolic substrate selection.

\section{Introduction}


Inhibition of the sodium-glucose co-transporter type 2 (SGLT2) has received growing acceptance as a novel, safe, and effective means to improve glycemic control in patients with type 2 diabetes. SGLT2 is a symport transport protein found primarily in the proximal tubule of the kidney where it is responsible for the majority of glucose reabsorption [1]. Thus, inhibition of SGLT2 lowers the renal glucose threshold and reduces blood glucose levels by promoting glycosuria. Unexpectedly, SGLT2 inhibitor therapy is also beneficial for patients with cardiovascular disease (CVD). Results from EMPA-REG OUTCOME, a clinical trial to establish the effects of the SGLT2 inhibitor empagliflozin (EMPA) on CVD outcomes in patients with type 2 diabetes at high risk of CVD, demonstrated marked reductions in mortality and rates of hospitalization due to heart failure in patients taking empagliflozin compared with placebo [2]. More recent large-scale clinical trials evaluating CVD-related outcomes of the SGLT2 inhibitors canagliflozin (CANVAS) [3] and dapagliflozin (DECLARE-TIMI 58) [4] produced similar findings, demonstrating that the effects on mortality and heart failure hospitalizations are a class effect and not specific to one inhibitor. Further evidence in this regard came from the CVD-REAL study, a real-world evidence-based study where total mortality and heart failure hospitalization rates were compared among new users of SGLT2 inhibitor therapy and patients taking other glucose lowering medications [5]. The study included data from approximately 310,000 patients where roughly half were taking one of three SGLT2 inhibitors, canagliflozin, dapagliflozin or empagliflozin. SGLT2 inhibitor-treated patients displayed a $51 \%$ reduction in all-cause mortality and 39\% reduction in hospitalization due to heart failure [5]. The beneficial effects of SGLT2 inhibitors on CVD also extend to patients with established heart failure, regardless of whether or not they have type 2 diabetes [6]. While the preponderance of evidence demonstrates a clear beneficial effect of SGLT2 inhibitor therapy on CVD-related outcomes, the underlying mechanism(s) for these observed benefits remain unclear.

A large number of putative mechanisms for the CVD protective effects of SGLT2 inhibitors are proposed and are the topic of recent reviews [7-9]. Several proposed mechanisms focus on changes in cardiac metabolism that restore bioenergetic capacity and improve cardiac efficiency, both of which decline during diabetic cardiomyopathy and heart failure $[10,11]$. Previous studies exploring a metabolic basis for the CVD-protective effects of EMPA relied on static measures of cardiac or plasma metabolites or changes in gene expression, or ex vivo approaches utilizing isolated cells or perfused working hearts [1215]. In order to understand whether changes in cardiac metabolism in response to EMPA occur in vivo, we applied a stable isotope tracing approach in awake mice under physiological conditions, in order to measure cardiac-specific rates of relative glucose and fatty acid oxidation during fasting and in response to hyperinsulinemic-euglycemic clamp.

\section{Materials And Methods}

\section{Animal care and use}

Mice were housed and studied at the University of Pittsburgh according to guidelines established by the Institutional Care and Use Committee. All diets, interventions and experimental procedures were reviewed and approved prior to studies. Age-matched, high-fat diet-fed (HFD; Research Diets D12492 60\% kcal fat) 
mice and low-fat diet (LFD; Research Diets D12450B 10\% kcal fat) were purchased from Jackson Labs (stock numbers 380050 and 380056, respectively). Mice were 24 weeks old at the time of arrival corresponding to 18 weeks of custom diet feeding. After two weeks recovery, LFD mice were maintained on LFD and HFD mice were randomly assigned to continue HFD or HFD supplemented with EMPA (HFD + E) at a concentration chosen to deliver $10 \mathrm{mg} / \mathrm{kg} / \mathrm{d}$ for four weeks. Thus, mice were 30 weeks old at the time of study and fed custom diets for 24 weeks where the last four weeks included empagliflozin the $\mathrm{HFD}+\mathrm{E}$ group. Urine collection and metabolic cage studies were performed two weeks after initiating drug treatment. Metabolic cage studies consisted of $72 \mathrm{~h}$ of analysis in the Columbus Labs Comprehensive Lab Animal Monitoring System. Body composition was measured by ${ }^{1} \mathrm{H}-\mathrm{NMR}$. For fasting/re-feeding studies, mice were fasted overnight and euthanized at 7am or fasted overnight and refed for one hour prior to euthanasia.

\section{Biochemical analyses}

Urine and plasma glucose levels were measured by the glucose oxidase method using the Analox GM9. Plasma insulin was measured using the Stellux chemiluminescent insulin ELISA. Plasma glucagon levels were measured using ELISA Kit (Millipore, EZGLU-30K). Plasma fatty acid and $\beta$-hydroxybutyrate levels were measured spectrophotometrically using commercially available kits from Wako and Sigma (MAK143), respectively.

\section{Echocardiography}

Echocardiography was performed using the Vevo 3100 (Visualsonics) in isofluorane-anesthetized mice. Cardiac contractile function and structure were measured by M-mode echocardiography, and data were analyzed by Vevo LAB software.

\section{Coronary artery ligations}

Mice underwent open thoracotomy to place a suture around the left anterior descending artery and left loose (sham) or tightly tied (coronary artery ligation), as previously described [16]. Briefly, mice were anesthetized, intubated, ventilated and a small incision was made on the left chest through the fourth intercostal space. The pericardium was opened and the left anterior descending coronary artery was tied off at its mid-segment with a suture to induce myocardial infarction. The suture was left intact for seven days after which the mice were euthanized for heart collection and dissection of the infarct, peri-infarct and remote heart regions.

\section{Gene expression}

For quantitative PCR studies, RNA was isolated from flash-frozen pulverized heart using TRIzol reagent, followed by cDNA synthesis, including DNase pre-treatment, using QuantiTect Reverse Transcriptase Kit (Qiagen). Quantitative PCR was performed using the Applied Biosystems QuantStudio3 RT-PCR System and PowerUp SYBR Green Master Mix (Thermo Fisher). Primer sequences were designed with Primers3web (https://primer3.ut.ee/) or purchased from Qiagen. Sequences for commercial primers are proprietary. Sequences for designed primers were as follows: Slc2a1(Glut1) (F:5'- 
TTGTTGTAGAGCGAGCTGGA-3' R:5'- ATGGCCACGATGCTCAGATA-3'); Slc2a4(Glut4) (F:5'-

CTGGGCTTGGAGTCTATGCT-3' R:5'- CGCTTTAGACTCTTTCGGGC-3'); and Cpt1b (F:5'-

GTCGCTTCTTCAAGGTCTGG-3' R:5'- AAGAAAGCAGCACGTTCGAT-3').

\section{Western blotting}

Frozen, pulverized heart was homogenized in RIPA buffer (150 mM NaCl, $1.0 \%$ Triton X-100, 0.5\% sodium deoxycholate, $0.1 \%$ sodium dodecyl sulfate, $50 \mathrm{mM}$ Tris, $\mathrm{pH} 8.0$ ) and centrifuged at $4^{\circ} \mathrm{C}, 1,000 \mathrm{xg}$ to produce a post-nuclear supernatant. Protein concentration of the lysate was determined using BCA protein assay and equal protein was loaded and resolved using Bolt Bis-Tris Plus gels prior to transfer to nitrocellulose membranes for incubation with antibodies as noted below. Blots were developed with Licor Odyssey CLx using Licor IRDye goat secondary antibodies and analyzed using Licor Image Studio Software (Version 5.2). Primary antibodies were as follows: LC3A/B (4108), Cell Signaling, 4108S; GAPDH (FL-335), Santa Cruz, SC-25778; Akt (pan) (40D4), Cell Signaling, 2920S; p-Akt (pSer473), Cell Signaling, 4060P; PDH (C54G1), Cell Signaling, 3205; p-PDH (Ser293), Cell Signaling, 37115.

\section{Working heart study}

Studies were performed as previously described [17]. Briefly, Krebs-Henseleit (KH) Buffer (118 mM NaCl, $25 \mathrm{mM} \mathrm{NaHCO}_{3}, 0.5 \mathrm{mM} \mathrm{Na}-\mathrm{EDTA}, 5 \mathrm{mM} \mathrm{KCl}, 1.2 \mathrm{mM} \mathrm{KH}_{2} \mathrm{PO}_{4}, 1.2 \mathrm{mM} \mathrm{MgSO}_{4}, 2.5 \mathrm{mM} \mathrm{CaCl}_{2}, 11 \mathrm{mM}$ glucose and $0.4 \mathrm{mM}$ oleate) was used to perfuse ex vivo beating heart from 16-week old, LFD-fed C57BL/ 6 mice via normothermic crystalloid perfusion. Isotopically labeled glucose ([U $\left.{ }^{14} \mathrm{C}\right]-\mathrm{D}$-glucose) and BSA bound oleic acid $\left(\left[9,10-{ }^{3} \mathrm{H}(\mathrm{N})\right]\right.$-oleic acid) were added to the $\mathrm{KH}$ buffer before perfusion. After perfusion for $15 \mathrm{~min}$, the coronary effluent was collected for analysis. Ventricular global contractility was simultaneously measured by pressure catheter (Millar Mikro-Tip). Metabolic byproducts of glucose $\left({ }^{14} \mathrm{CO}_{2}\right)$ and fatty acid $\left({ }^{3} \mathrm{H}_{2} \mathrm{O}\right)$ oxidation were quantitatively recovered from the coronary effluent for calculation of the glucose and fatty acid oxidation rates.

\section{Cardiac-specific substrate utilization and stable isotope mass spectrometry}

Isotope infusion and hyperinsulinemic euglycemic clamp studies were performed according to recommendations of the Mouse Metabolic Phenotyping Consortium [18]. Briefly, mice underwent surgery to implant an indwelling catheter in the right jugular vein and recovered five days prior to study. Mice were fasted six hours in the morning prior to study. To determine cardiac-specific mitochondrial substrate use and metabolic flexibility, mice were infused with $\left[\mathrm{U}^{13} \mathrm{C}\right]$-glucose at a rate of $1 \mathrm{mg} \cdot \mathrm{kg}^{-1} \cdot \mathrm{min}^{-1}$ for $120 \mathrm{~min}$ to achieve steady-state for the basal or fasted state, or underwent a 120 min hyperinsulinemiceuglycemic clamp where $\left[\mathrm{U}^{13} \mathrm{C}\right]$-glucose $\left(25 \%\right.$ enriched ${ }^{13} \mathrm{C}$ enriched $20 \%$ dextrose) was infused to maintain euglycemia. Insulin was given as a primed/continuous infusion (Novolin-R, Novo Nordisk; prime dose: $30 \mathrm{mU} / \mathrm{kg}$ over $3 \mathrm{~min}$; continuous dose: $4.5 \mathrm{mU} \bullet \mathrm{kg}^{-1} \bullet \mathrm{min}^{-1}$ ). Plasma glucose levels were checked using blood collected by tail vein massage every 10 min during study. After each study, mice were sacrificed by intravenous pentobarbital injection and hearts collected within $15 \mathrm{sec}$ of euthanasia and 
snap frozen in liquid nitrogen. Frozen hearts were pulverized and processed for analysis by liquid chromatography mass spectrometry (LC-MS) to determine enrichments of $\left[1,2,3-{ }^{13} \mathrm{C}\right]$-pyruvate and $[1,2-$ ${ }^{13} \mathrm{C}$-acetyl-CoA for the calculation of carbohydrate flux through pyruvate dehydrogenase $\left(\mathrm{V}_{\mathrm{PDH}}\right)$ relative to total mitochondrial TCA cycle flux $\left(\mathrm{V}_{\mathrm{TCA}}\right)$, or $\mathrm{V}_{\mathrm{PDH}} / \mathrm{V}_{\mathrm{TCA}}$, as previously described $[19,20]$. Briefly, the infused $\left[\mathrm{U}-{ }^{13} \mathrm{C}\right]$-glucose tracer is metabolized to $\left[1,2,3-{ }^{13} \mathrm{C}\right]$-pyruvate in heart, which then enters the TCA cycle where it is converted to $\left[1,2-{ }^{13} \mathrm{C}\right]$-acetyl-CoA. The ratio of $\left[1,2-{ }^{13} \mathrm{C}\right]$-acetyl-CoA to $\left[1,2,3^{-13} \mathrm{C}\right]$-pyruvate therefore reflects $V_{P D H}$ relative to $V_{T C A}$, such that a ratio of one indicates $100 \%$ glucose oxidation and any reduction in this ratio reflects dilution of $\left[1,2-{ }^{13} \mathrm{C}\right]$-acetyl-CoA produced from $\left[1,2,3^{-13} \mathrm{C}\right]$-pyruvate by unlabeled acetyl-CoA from other sources, primarily fatty acid oxidation. Due to difficulties in reliably measuring isotopologues of acetyl-CoA and pyruvate related to pool size in the fasted samples during LC/MS, $\left[4,5^{-13} \mathrm{C}\right]$-glutamate and $\left[1,2,3^{-13} \mathrm{C}\right]$-lactate were used as surrogates for $\left[1,2^{-13} \mathrm{C}\right]$-acetyl-CoA and $\left[1,2,3^{-13} \mathrm{C}\right]$ pyruvate, respectively, as previously described $[19,21]$. Isotopologues of $\left[1,2^{13} \mathrm{C}\right]$-acetyl-CoA and $\left[1,2,3-{ }^{13} \mathrm{C}\right]$-lactate were used for calculations in insulin clamped mice.

Metabolic quenching was performed by mechanical homogenization of tissue in liquid nitrogen. The polar metabolite pool was extracted by vortexing in ice cold $80 \%$ methanol in water with $0.1 \%$ formic acid at a ratio of $15 \mu \mathrm{L}$ per $\mathrm{mg}$ of dry tissue. Deuterated (D3)-creatinine and (D3)-alanine, (D4)-taurine (SigmaAldrich) were added to the sample lysates as internal standards for a final concentration of $10 \mu \mathrm{M}$. The supernatant was cleared of protein by centrifugation at $16,000 \times g$, dried under nitrogen gas and resuspended in $100 \mathrm{uL}$ water with $0.1 \%$ formic acid. Analyses were performed by untargeted LC-HRMS. Briefly, samples were injected via a Thermo Vanquish UHPLC and separated over a reversed phase Thermo HyperCarb porous graphite column $(2.1 \times 100 \mathrm{~mm}, 3 \mu \mathrm{m}$ particle size $)$ maintained at $55^{\circ} \mathrm{C}$. For the 20-minute LC gradient, the mobile phase consisted of the following: solvent $A$ (water / $0.1 \% \mathrm{FA}$ ) and solvent $B(A C N$ / $0.1 \%$ FA). The gradient was the following: 0-1 min 1\% B, increase to $15 \%$ B over 5 minutes, continue increasing to $98 \%$ B over 5 minutes, hold at $98 \%$ B for five minutes, re-equilibrate at $1 \%$ $\mathrm{B}$ for five minutes. The Thermo IDX tribrid mass spectrometer was operated in both positive and negative ion mode, scanning in ddMS 2 mode ( $2 \mu$ scans) from 70 to $800 \mathrm{~m} / \mathrm{z}$ at 120,000 resolution with an AGC target of 2e 5 for full scan, 2e4 for MS2 scans using HCD fragmentation at stepped 15, 35, 50 collision energies. Source ionization setting was 3.0 and $2.4 \mathrm{kV}$ spray voltage respectively for positive and negative mode. Source gas parameters were 35 sheath gas, 12 auxiliary gas at $320^{\circ} \mathrm{C}$, and 8 sweep gas. Calibration was performed prior to analysis using the PierceTM FlexMix Ion Calibration Solutions (Thermo Fisher Scientific). Integrated peak areas were then extracted manually using Quan Browser (Thermo Fisher Xcalibur ver. 2.7).

\section{Statistical analyses}

Data shown are the mean \pm s.e.m. and were compared by one-way ANOVA followed by Tukey's multiple comparison test or Student's t-test where noted. For all comparisons $p<0.05$ was considered significant.

\section{Results}


EMPA promotes glucosuria and whole-body fat oxidation. Mice fed a long-term HFD exhibit alterations in cardiac metabolism consistent with changes observed in patients with diabetic cardiomyopathy, namely increased fatty acid oxidation, decreased glucose oxidation, and impaired mitochondrial bioenergetics [22]. We therefore studied the effects of four-weeks of EMPA treatment in mice fed HFD for 24 weeks and included an age-matched LFD-fed group as a comparator. As expected, urine glucose concentrations were increased 7- and 5-fold in HFD + E compared with LFD and HFD mice, respectively (Fig. 1A; $P<0.001$ ). Delivering EMPA via the diet did not affect feeding, as there were no differences in feeding between groups (Fig. 1B). The respiratory exchange ratio, indicative of relative glucose and fat oxidation, was reduced in HFD compared with LFD mice, demonstrating increased whole-body fat oxidation in the HFD group (Fig. 1C; $\mathrm{P}<0.01$ ). The respiratory exchange ratio was further reduced in HFD + E mice compared with HFD mice (Fig. 1C; $\mathrm{P}<0.05$ ) consistent with previous reports in rodents and humans demonstrating that SGLT2 inhibition promotes whole-body fat oxidation [23, 24]. There were no differences in energy expenditure or activity between groups during the metabolic cage studies (data not shown). Body weight and fat mass were significantly increased in HFD and HFD + E compared with LFD mice (Fig. 1D\&F), while there were no differences in lean mass between groups (Fig. 1E). There was no difference in body weight or fat mass between HFD and HFD + E mice likely due to the relatively low dose $\left(10 \mathrm{mg} \bullet \mathrm{kg}^{-1} \cdot \mathrm{day}^{-}\right.$ ${ }^{1}$ ) and short duration (4 weeks) of EMPA treatment.

Previous studies reported increased plasma glucagon levels, as well as ketone body levels in response to SGLT2 inhibitor treatment, and increased cardiac ketone utilization is thought to contribute to improved CVD outcomes in patients treated with SGLT2 inhibitor therapy [25]. We therefore measured plasma levels of a number of hormonal and metabolic factors in fasted and re-fed LFD, HFD and HFD + E mice. The fasting/re-feeding paradigm produced predicted increases in plasma glucose and insulin levels (Fig. 2A\&B), as well as reductions in fatty acid and ketone levels in LFD mice (Fig. 2D\&E), indicative of a successful protocol. Fasting plasma glucose levels were significantly increased in HFD and HFD +E compared with LFD mice (Fig. 2A; $\mathrm{P}<0.01$ ), while there were no differences in plasma glucose levels following re-feeding between groups (Fig. 2A). Plasma insulin levels were significantly increased in HFD and HFD + E compared with LFD mice in both fasted and re-fed mice (Fig. 2B). There were no differences in plasma glucagon levels between groups in either the fasted or re-fed states, although plasma glucagon levels in fasted HFD + E mice appeared modestly elevated compared with LFD and HFD mice (Fig. 3C; P = 0.11). Fasted plasma fatty acid levels were significantly reduced in HFD and HFD + E mice compared with LFD (Fig. 2D; $P<0.001$ ), while there were no differences in re-fed plasma fatty acid levels between groups (Fig. 2D). Lastly, plasma levels of $\beta$-hydroxybutyrate were not different between groups in either the fasted or re-fed state (Fig. 2E).

Cardiac hypertrophy and susceptibility to ischemic stress are improved in EMPA-treated mice. Fatty acids are a less efficient metabolic substrate compared with glucose [26] and reduced cardiac efficiency and increased reliance on fatty acid oxidation during diabetic cardiomyopathy precede and therefore likely contribute to cardiac hypertrophy [27]. We therefore assessed ventricular mass and dimensions as surrogates of cardiac hypertrophy using echocardiography in anesthetized mice. During diastole, the 
interventricular septum width (IVSd) was significantly increased in HFD and HFD + E compared with LFD mice, and reduced in HFD + E compared with HFD mice (Fig. $3 A$; $P<0.001, P<0.05$ and $P<0.05$, respectively). There were no differences in the left ventricle internal dimension (LVID) or the left ventricular posterior wall (LVPW; Fig. 3B\&C). During systole, the IVS and LVPW were significantly increased in HFD compared with LFD mice, while there were no differences between HFD + E and LFD mice (Fig. 3D\&F), and there were no differences in LVID between groups (Fig. 3E). The estimated left ventricular mass (LV mass) was significantly increased in HFD compared with LFD mice, and reduced in HFD + E compared with HFD mice (Fig. 3G; $\mathrm{P}<0.001$ and $\mathrm{P}<0.05$, respectively). Lastly, there were no detected differences between groups in fractional shortening or ejection fraction measured during echocardiography under anesthesia (Fig. 3H\&l).

To determine whether EMPA protected against a cardiac-specific stress in our model, we performed coronary artery ligations to induce ischemia without reperfusion and sacrificed mice seven days after the procedure in order to isolate the area of infarct, peri-infarct and remote heart during dissection.

Expression of the cardiac stress-related genes B-type natriuretic peptide $(B n p)$ and atrial natriuretic peptide (Anp) appeared elevated in the area of infarct compared with sham treated mice from each group, indicative of a successful procedure (Fig. 4A\&B). Bnp expression was significantly different in the remote heart (Fig. 4A; $P<0.05$ ). Multiple comparison testing did not detect significant differences between groups, although there were trends for increased Bnp expression in HFD compared with LFD and HFD + E (Fig. 4A; $P=0.07$ and $P=0.06$, respectively). Similar observations were made for Anp expression in remote heart, where the effect of group trended towards significance (Fig. 4B; $P=0.05$ ), and multiple comparison testing detected similar trends of increased Anp expression in HFD compared with LFD and $\mathrm{HFD}+\mathrm{E}$ (Fig. 4B; $\mathrm{P}=0.07$ and $\mathrm{P}=0.08$, respectively). Lastly, expression of Bnp and Anp in the area of infarct and peri-infarct did not differ between groups, despite a similar pattern of expression compared with changes observed in the remote heart (Fig. 4A\&B).

EMPA restores cardiac metabolic flexibility. Cardiac-specific substrate selection was measured after a $6 \mathrm{~h}$ morning fast or during a hyperinsulinemic euglycemic-clamp by infusing mice with $\left[\mathrm{U}^{13} \mathrm{C}\right]$-glucose. Plasma glucose levels were matched between groups during the hyperinsulinemic euglycemic clamp (Fig. 5A upper panel) and the glucose infusion rate (GIR) required to maintain euglycemia was significantly greater in LFD compared with HFD and HFD + E, demonstrating impaired whole-body insulin sensitivity in the HFD and HFD + E mice (Fig. 5A lower panel and 5B; $P<0.001$ ). In the fasted state, there were no differences in $\mathrm{V}_{\mathrm{PDH}} / \mathrm{V}_{\mathrm{TCA}}$ between groups and the measured value of approximately 0.2 reflected $20 \%$ glucose and $80 \%$ fatty acid utilization (Fig. 5C). During the hyperinsulinemic euglycemic clamp, $\mathrm{V}_{\mathrm{PDH}} / \mathrm{V}_{\mathrm{TCA}}$ was significantly reduced in HFD compared with LFD and HFD + E mice, reflecting increased glucose utilization in LFD and HFD + E mice in response to insulin (Fig. 5D; $P<0.05$ and $P<0.01$, respectively).

Metabolic flexibility and cardiac substrate selection are regulated by multiple factors including the expression and activity of key mediators of substrate selection, such as PDH and CPT1, as well as the availability of metabolic substrates and subsequent effects on allostery [28]. Insulin resistance plays an 
important role in obesity-associated metabolic inflexibility by reducing the amount of glucose transported and thus oxidized by cell types expressing the insulin-responsive glucose transporter GLUT4, such as skeletal and cardiac muscle [29]. To determine whether the observed differences in cardiac metabolic flexibility were associated with changes in insulin sensitivity in LFD and HFD + E compared with HFD mice, we measured changes in cardiac Akt phosphorylation in response to fasting and re-feeding. There were no differences in phospho-Akt during fasting (Fig. 5E\&F); however, phospho-Akt was significantly increased in HFD + E compared with HFD mice, and there was a trend towards increased levels in LFD compared with HFD (Fig. 5E\&F; $P<0.05$ and $P=0.07$, respectively). The fold-change in phospho-Akt in response to re-feeding was significantly reduced in HFD compared with LFD and HFD + E, demonstrating impaired insulin signaling in HFD mice that was reversed by EMPA (Fig. 5G; $P<0.05$ and $P<0.01$ ).

Next, we measured changes in key regulators of glucose and fatty acid oxidation, namely PDH and CPT1B. Phosphorylation of PDH, which leads to inhibition and reduced glucose oxidation, was similar between groups under fasted and re-fed conditions (Fig. 6A-B). Expression of $C p t 1 b$, which facilitates mitochondrial fatty acid import and oxidation, was similar between groups in the fasted state, whereas in the re-fed state, Cpt1b expression was greater in HFD compared with LFD mice (Fig. 6C; $P<0.05$ ). Expression of the glucose transporter Glut4 was significantly different between groups in both the fasted and re-fed state, where G/ut4 expression was significantly less in HFD + E compared with LFD mice (Fig. 6D; $P<0.05$ ), and levels tended to be reduced in HFD compared with LFD in the fasted state (Fig. 6D; $P=0.07)$. Changes in Glut1 expression followed a similar pattern as Glut4 and were significantly reduced in HFD compared with LFD mice in the fasted state, whereas expression in HFD + E tended to be reduced, although not significantly (Fig. 6E; $\mathrm{P}<0.05, \mathrm{P}<0.07$ ). Following re-feeding, Glut1 expression was significantly reduced in HFD and HFD + E compared with LFD mice (Fig. 6E; P $<0.01$ ). Changes in cardiac autophagy are implicated in the beneficial effects of SGLT2 inhibitor therapy on CVD [30], so we also measured changes in LC3II levels in response to fasting and re-feeding. LC3II levels normalized to GAPDH were greater in the fasted state compared with re-fed state, as would be expected, and there were no differences between groups in either dietary state (Fig. 6F-G).

The metabolite 1,5-anhydroglucitol (1,5-AG) competes with glucose for reabsorption by the kidney such that SGLT2 inhibitor therapy, which raises renal tubular glucose concentrations, reduces plasma 1,5-AG levels by promoting 1,5-AG urinary excretion [31-33]. Phosphorylation of 1,5-AG produces 1,5-AG-6phosphate (1,5-AG-6P), which inhibits hexokinase and in turn glycolysis [34, 35]. We therefore investigated whether reduced 1,5-AG in HFD + E mice may contribute to increased cardiac glucose utilization by relieving inhibition of hexokinase. Consistent with previous reports regarding the effects of renal tubular glycemia on 1,5-AG levels in plasma [31-33], we found that cardiac concentrations of 1,5AG were significantly reduced in HFD compared with LFD mice, and that 1,5-AG levels were also significantly reduced in HFD + E mice compared with both LFD and HFD mice (Fig. 7A; $P<0.0001$ ). Next, to determine whether increasing concentrations of 1,5-AG could inhibit glucose oxidation in cardiomyocytes, we measured rates of glucose oxidation in $\mathrm{H} 9 \mathrm{c} 2$ cells cultured in normal $(5 \mathrm{mM})$ and high $(20 \mathrm{mM})$ glucose in the presence of increasing concentrations of 1,5-AG (0-36 mM). In the presence of $5 \mathrm{mM}$ glucose, $36 \mathrm{mM}$ 1,5-AG appeared to reduce rates of glucose oxidation by approximately $50 \%$, 
however, the result was not significant (Fig. 7B; $P=0.17$ ). There was no effect of 1,5-AG at lower concentrations nor at any concentration in the presence of $20 \mathrm{mM}$ glucose (Fig. 7B). Similar studies performed in the ex vivo working heart system demonstrated no effect of increasing 1,5-AG levels on glucose oxidation, however, oleate oxidation rates were reduced in the presence of $12 \mathrm{mM}$ 1,5-AG (Fig. 7C$D ; P<0.01)$. Lastly, 1,5-AG levels had no effect on ventricular function as measured by the $d P / d T$ maximum and minimum values determined during the working heart study (Fig. 7E\&F).

\section{Discussion}

In summary, we found that in the fasted state, relative rates of cardiac-specific glucose versus fatty acid utilization were similar in lean and diet-induced obese mice with or without EMPA treatment (Fig. 5C). The ability to increase glucose utilization in response to a physiological-stimuli, hyperinsulinemia, was impaired in the obese compared with lean mice and partially restored by EMPA treatment (Fig. 5D). Approximation of the fold change in relative glucose utilization in clamped versus fasted mice serves as an index of metabolic flexibility. LFD-fed mice displayed a 3.2-fold increase compared with 1.3- and 2.3fold increases in HFD and HFD + E mice, demonstrating loss of cardiac-specific metabolic flexibility during obesity that was restored by EMPA. The improved cardiac glucose utilization and metabolic flexibility in EMPA-treated mice was associated with reduced cardiac hypertrophy (Fig. 3A\&G), suggesting that the ability to use multiple metabolic substrates for energy production, particularly glucose, improved cardiac contractile efficiency and lessened compensatory hypertrophy. EMPA-treated mice were protected from ischemic stress (Fig. 4A-B), which may also result from their ability to increase glucose utilization in response to stress, thereby maximizing ATP production when oxygen levels are limiting and preventing cell death and subsequent adverse cardiac remodeling. Overall, our data support the notion that SGLT2 inhibitor therapy produces metabolic changes in heart that likely contribute to the CVD-protective effects of this class of drug.

While there is general agreement that the failing heart is bioenergetically compromised, in part due to altered metabolic substrate utilization where the heart favors metabolism of glucose over fatty acids [10, 36], there is less agreement as to whether similar changes occur during diabetic cardiomyopathy prior to heart failure [37]. In general, studies performed in vivo using isotope tracing and preclinical animal models of insulin resistance demonstrated reduced cardiac glucose utilization and increased fatty acid utilization [20,38-42], whereas studies performed ex vivo using models of insulin insufficiency detected reduced cardiac fatty acid utilization $[43,44]$. Our data add to the growing body of in vivo evidence demonstrating that glucose metabolism is reduced and fatty acid metabolism is increased in models of diabetic cardiomyopathy, which likely results from cardiac insulin resistance, as well as increased plasma fatty acid levels that occur in these models. And although diabetic cardiomyopathy and heart failure differ from a metabolic standpoint in terms of substrate selection, both are characterized by the loss of metabolic flexibility or the use of the correct metabolic fuel given a specific physiological condition. Our data therefore suggest that the CVD-protective effects of EMPA may result in part from restored cardiac metabolic flexibility. 
Although our study cannot account for a single, mechanistic change by which EMPA restored cardiac metabolic flexibility, we observed a small number of changes in specific pathways that may contribute to the effect. First, cardiac-specific insulin sensitivity was improved by EMPA treatment (Fig. 5E-F), which would facilitate increased GLUT4-mediated glucose transport and thus glucose utilization. Second, systemic insulin sensitivity was mildly improved by EMPA (Fig. 5A-B) and the post-prandial suppression of adipose tissue lipolysis by insulin, calculated from the percent change in plasma fatty acid levels shown in Fig. 2D, was partially restored by EMPA; plasma fatty acid levels were reduced following refeeding by $60 \%$ in LFD-fed mice compared with $25 \%$ in HFD and $40 \%$ in HFD + E mice. Thus, improved adipose tissue insulin sensitivity may have reduced fatty acid delivery to the heart and thus utilization in EMPA treated mice. Unfortunately, we did not collect sufficient plasma during the hyperinsulinemic euglycemic clamp to measure plasma fatty acid levels. Finally, we did not observe changes in PDH protein levels or phosphorylation, expression of $C p t 1 \beta$ or G/ut1/4, nor markers of cardiac autophagy, that could account for changes in substrate use, suggesting they did not contribute to the observed phenotype (Fig. 6A-G).

Hexokinase phosphorylates glucose to glucose-6-phosphate (G6P) in the first committed step in glycolysis. Inhibition of hexokinase by cytosolic accumulation of 1,5-AG-6P causes neutrophil dysfunction and apoptosis due to a loss of glycolysis in two rare autosomal, recessively inherited inborn errors of carbohydrate metabolism known as glycogen storage disease type lb (GSD-Ib) and congenital neutropenia type $4[45,46]$. The metabolite 1,5-AG-6P accumulates in the cytosol in GSD-Ib due to mutations in glucose-6-phosphate translocase (G6PT), which normally transports 1,5-AG-6P into the endoplasmic reticulum where it is dephosphorylated by glucose-6-phosphatase catalytic subunit 3 (G6PC3) to produce 1,5-AG. During congenital neutropenia type 4, 1,5-AG-6P accumulates in the cytosol due to mutations in G6PC3. The observation that 1,5-AG-6P, which is produced from 1,5-AG, can accumulate in cells and limit glucose metabolism led us to hypothesize that the reduction in cardiac 1,5AG levels in EMPA treated mice may relieve partial or mild inhibition of hexokinase and facilitate the increased glucose utilization observed during the clamp. However, increasing concentrations of 1,5-AG to levels well outside the physiological range in two different model systems, namely H9c2 cells and the ex vivo working heart, had no effect on glucose utilization (Fig. 7). The lack of effect may be due to the acute timeframe of the studies, which may not allow for significant accumulation of 1,5-AG-6P that presumably occurs in vivo, or may reflect an enhanced capacity to buffer or reduce intracellular 1,5-AG-6P via G6PC3 activity in cardiomyocytes compared with neutrophils. Alternatively, our results suggest that the known effects of SGLT2 inhibitor therapy on 1,5-AG levels do not contribute to changes in cardiac metabolism.

In conclusion, by using a novel approach to measure relative glucose versus fatty acid utilization in heart in vivo, we found that glucose utilization and metabolic flexibility are impaired in obese, insulin resistant mice compared with lean controls. More importantly, we found that SGLT2 inhibitor therapy restored insulin-stimulated glucose utilization and metabolic flexibility in heart, changes that were associated with reduced ventricular hypertrophy and protection from ischemic stress. These observations add to the growing list of potential mechanisms of action by which SGLT2 inhibitors are CVD-protective, and more 
broadly suggest that interventions that restore metabolic flexibility or glucose utilization in heart during diabetic cardiomyopathy may produce similar beneficial effects.

\section{Declarations}

\section{Ethics approval and consent to participate}

All studies involving mice were reviewed and approved by the University of Pittsburgh Institutional Animal Care and Use Committee prior to studies.

\section{Consent for publication}

Not applicable.

\section{Availability of data and materials}

The datasets in the current study are available from the corresponding author on reasonable request.

\section{Competing interests}

The authors declare that they have no competing interests.

\section{Funding}

This work was supported by the Center for Metabolism and Mitochondrial Medicine (C3M) and funding provided by the Pittsburgh Foundation (MR2020 109502), the University of Pittsburgh Rodent Ultrasonography Core through support from the NIH/OD S10 Instrumentation Program (OD023684), and the Health Sciences Metabolomics Core at the University of Pittsburgh and funding provided by the $\mathrm{NIH}$ (S100D023402).

\section{Authors' contributions}

$\mathrm{BX}, \mathrm{WR}, \mathrm{AM}, \mathrm{BH}$, and IS performed experiments involving mice including diet/drug delivery, body weight/composition measures, fasting/re-feeding studies and $\left[\mathrm{U}^{13} \mathrm{C}\right]$-glucose infusions; $\mathrm{BX}, \mathrm{WR}, \mathrm{MA}, \mathrm{MP}$ and EL performed plasma biochemistry, gene expression and protein expression studies; BC and LG performed coronary artery ligations and subsequent isolation of infarct/peri-infarct, remote heart samples; SM and SW performed LC-MS measurements of metabolites; BX, IS and MJ analyzed data; BX, SW, IS, CO and MJ interpreted results; CO, IS and MJ designed experiments; WR, BX, MP, IS and MJ wrote the manuscript; all authors read and approved the final manuscript.

\section{Acknowledgements}

Not applicable. 


\section{References}

1. Vallon V, Platt KA, Cunard R, Schroth J, Whaley J, Thomson SC, Koepsell H, Rieg T. SGLT2 mediates glucose reabsorption in the early proximal tubule. J Am Soc Nephrol. 2011;22:104-12.

2. Zinman B, Wanner C, Lachin JM, et al. Empagliflozin, Cardiovascular Outcomes, and Mortality in Type 2 Diabetes. N Engl J Med. 2015;373:2117-28.

3. Neal B, Perkovic V, Mahaffey KW, de Zeeuw D, Fulcher G, Erondu N, Shaw W, Law G, Desai M, Matthews DR. Canagliflozin and Cardiovascular and Renal Events in Type 2 Diabetes. N Engl J Med. 2017;377:644-57.

4. Wiviott SD, Raz I, Bonaca MP, et al. Dapagliflozin and Cardiovascular Outcomes in Type 2 Diabetes. N Engl J Med. 2019;380:347-57.

5. Kosiborod M, Cavender MA, Fu AZ, et al. Lower Risk of Heart Failure and Death in Patients Initiated on Sodium-Glucose Cotransporter-2 Inhibitors Versus Other Glucose-Lowering Drugs: The CVD-REAL Study (Comparative Effectiveness of Cardiovascular Outcomes in New Users of Sodium-Glucose Cotransporter-2 Inhibitors). Circulation. 2017;136:249-59.

6. McMurray JJV, Solomon SD, Inzucchi SE, et al. Dapagliflozin in Patients with Heart Failure and Reduced Ejection Fraction. N Engl J Med. 2019;381:1995-2008.

7. Lopaschuk Gary D, Subodh V. (2020) Mechanisms of Cardiovascular Benefits of Sodium Glucose CoTransporter 2 (SGLT2) Inhibitors. JACC: Basic to Translational Science 5:632-644.

8. Lam Carolyn SP, Chanchal C, Vineeta A, Verma Subodh. SGLT-2 Inhibitors in Heart Failure: Current Management, Unmet Needs, and Therapeutic Prospects. Journal of the American Heart Association. 2019;8:e013389.

9. Perry RJ, Shulman GI. Sodium-glucose cotransporter-2 inhibitors: Understanding the mechanisms for therapeutic promise and persisting risks. J Biol Chem. 2020;295:14379-90.

10. Neubauer S. The Failing Heart - An Engine Out of Fuel. N Engl J Med. 2007;356:1140-51.

11. Jia Guanghong HMichaelA, Sowers James R. Diabetic Cardiomyopathy. Circ Res. 2018;122:624-38.

12. Verma Subodh R, Sonia, Ho Kim L, et al (2018) Empagliflozin Increases Cardiac Energy Production in Diabetes. JACC: Basic to Translational Science 3:575-587.

13. Shao Q, Meng L, Lee S, Tse G, Gong M, Zhang Z, Zhao J, Zhao Y, Li G, Liu T. Empagliflozin, a sodium glucose co-transporter-2 inhibitor, alleviates atrial remodeling and improves mitochondrial function in high-fat diet/streptozotocin-induced diabetic rats. Cardiovascular Diabetology. 2019;18:165.

14. Ho KL, Zhang L, Wagg C, et al. Increased ketone body oxidation provides additional energy for the failing heart without improving cardiac efficiency. Cardiovasc Res. 2019;115:1606-16.

15. Yurista SR, Silljé HHW, Oberdorf-Maass SU, Schouten E-M, Pavez Giani MG, Hillebrands J-L, van Goor $H$, van Veldhuisen DJ, de Boer RA, Westenbrink BD. Sodium-glucose co-transporter 2 inhibition with empagliflozin improves cardiac function in non-diabetic rats with left ventricular dysfunction after myocardial infarction. Eur J Heart Fail. 2019;21:862-73. 
16. McGaffin KR, Witham WG, Yester KA, Romano LC, O’Doherty RM, McTiernan CF, O’Donnell CP. Cardiac-specific leptin receptor deletion exacerbates ischaemic heart failure in mice. Cardiovasc Res. 2011;89:60-71.

17. Bakrania B, Granger J, Harmancey R. Methods for the Determination of Rates of Glucose and Fatty Acid Oxidation in the Isolated Working Rat Heart. Journal of visualized experiments: JoVE. 2016. https://doi.org/10.3791/54497.

18. Ayala JE, Samuel VT, Morton GJ, Obici S, Croniger CM, Shulman GI, Wasserman DH, McGuinness OP, NIH Mouse Metabolic Phenotyping Center Consortium. Standard operating procedures for describing and performing metabolic tests of glucose homeostasis in mice. Dis Model Mech. 2010;3:525-34.

19. Alves TC, Befroy DE, Kibbey RG, Kahn M, Codella R, Carvalho RA, Falk Petersen K, Shulman GI. Regulation of hepatic fat and glucose oxidation in rats with lipid-induced hepatic insulin resistance. Hepatology. 2011;53:1175-81.

20. Thapa D, Xie B, Zhang M, et al. Adropin treatment restores cardiac glucose oxidation in pre-diabetic obese mice. J Mol Cell Cardiol. 2019;129:174-8.

21. Shulman GI, Rossetti L, Rothman DL, Blair JB, Smith D. Quantitative analysis of glycogen repletion by nuclear magnetic resonance spectroscopy in the conscious rat. J Clin Invest. 1987;80:387-93.

22. Wright JJ, Kim J, Buchanan J, et al. Mechanisms for increased myocardial fatty acid utilization following short-term high-fat feeding. Cardiovasc Res. 2009;82:351-60.

23. Ferrannini E, Muscelli E, Frascerra S, Baldi S, Mari A, Heise T, Broedl UC, Woerle H-J. Metabolic response to sodium-glucose cotransporter 2 inhibition in type 2 diabetic patients. J Clin Invest. 2014;124:499-508.

24. Ferrannini E, Baldi S, Frascerra S, Astiarraga B, Heise T, Bizzotto R, Mari A, Pieber TR, Muscelli E. Shift to Fatty Substrate Utilization in Response to Sodium-Glucose Cotransporter 2 Inhibition in Subjects Without Diabetes and Patients With Type 2 Diabetes. Diabetes. 2016;65:1190-5.

25. Ferrannini E, Mark M, Mayoux E. CV Protection in the EMPA-REG OUTCOME Trial: A "Thrifty Substrate" Hypothesis. Diabetes Care. 2016;39:1108-14.

26. Lopaschuk GD, Verma S. Empagliflozin's Fuel Hypothesis: Not so Soon. Cell Metab. 2016;24:200-2.

27. Buchanan J, Mazumder PK, Hu P, Chakrabarti G, Roberts MW, Yun UJ, Cooksey RC, Litwin SE, Abel ED. Reduced Cardiac Efficiency and Altered Substrate Metabolism Precedes the Onset of Hyperglycemia and Contractile Dysfunction in Two Mouse Models of Insulin Resistance and Obesity. Endocrinology. 2005;146:5341-9.

28. Fillmore N, Mori J, Lopaschuk GD. Mitochondrial fatty acid oxidation alterations in heart failure, ischaemic heart disease and diabetic cardiomyopathy. Br J Pharmacol. 2014;171:2080-90.

29. Galgani JE, Moro C, Ravussin E. Metabolic flexibility and insulin resistance. American Journal of Physiology-Endocrinology Metabolism. 2008;295:E1009-17.

30. Esterline RL, Vaag A, Oscarsson J, Vora J. MECHANISMS IN ENDOCRINOLOGY: SGLT2 inhibitors: clinical benefits by restoration of normal diurnal metabolism? Eur J Endocrinol. 2018;178:R113-25. 
31. Balis DA, Tong C, Meininger G. Effect of canagliflozin, a sodium-glucose cotransporter 2 inhibitor, on

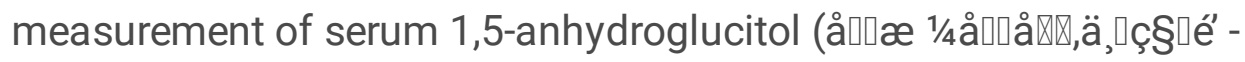

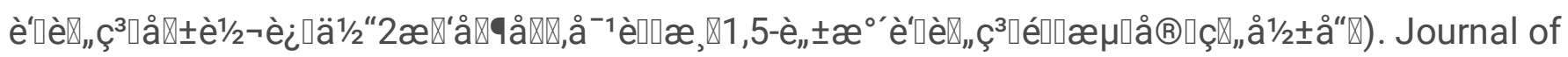
Diabetes. 2014;6:378-80.

32. Kappel BA, Moellmann J, Thiele K, et al. Human and mouse non-targeted metabolomics identify 1,5anhydroglucitol as SGLT2-dependent glycemic marker. Clin Transl Med. 2021;11:e470.

33. Usui M, Tanaka M, Takahashi H. 1,5-anhydroglucitol is a good predictor for the treatment effect of the Sodium-Glucose cotransporter 2 inhibitor in Japanese patients with type 2 diabetes mellitus. $\mathrm{J}$ Clin Transl Endocrinol. 2020;21:100233.

34. Wortmann SB, Van Hove JLK, Derks TGJ, et al. Treating neutropenia and neutrophil dysfunction in glycogen storage disease type lb with an SGLT2 inhibitor. Blood. 2020;136:1033-43.

35. Veiga-da-Cunha $M$, Chevalier N, Stephenne $X$, et al. Failure to eliminate a phosphorylated glucose analog leads to neutropenia in patients with G6PT and G6PC3 deficiency. PNAS. 2019;116:1241-50.

36. Neubauer S, Horn M, Cramer M, et al. Myocardial phosphocreatine-to-ATP ratio is a predictor of mortality in patients with dilated cardiomyopathy. Circulation. 1997;96:2190-6.

37. Sowton AP, Griffin JL, Murray AJ. Metabolic Profiling of the Diabetic Heart: Toward a Richer Picture. Front Physiol. 2019;10:639.

38. Mansor LS, Gonzalez ER, Cole MA, Tyler DJ, Beeson JH, Clarke K, Carr CA, Heather LC. Cardiac metabolism in a new rat model of type 2 diabetes using high-fat diet with low dose streptozotocin. Cardiovasc Diabetol. 2013;12:136.

39. Rohm M, Savic D, Ball V, Curtis MK, Bonham S, Fischer R, Legrave N, MacRae JI, Tyler DJ, Ashcroft FM. Cardiac Dysfunction and Metabolic Inflexibility in a Mouse Model of Diabetes Without Dyslipidemia. Diabetes. 2018;67:1057-67.

40. Le Page LM, Rider OJ, Lewis AJ, Ball V, Clarke K, Johansson E, Carr CA, Heather LC, Tyler DJ. Increasing Pyruvate Dehydrogenase Flux as a Treatment for Diabetic Cardiomyopathy: A Combined 13C Hyperpolarized Magnetic Resonance and Echocardiography Study. Diabetes. 2015;64:2735-43.

41. van den Brom CE, Huisman MC, Vlasblom R, et al. Altered myocardial substrate metabolism is associated with myocardial dysfunction in early diabetic cardiomyopathy in rats: studies using positron emission tomography. Cardiovasc Diabetol. 2009;8:39.

42. How O-J, Aasum E, Severson DL, Chan WYA, Essop MF, Larsen TS. Increased myocardial oxygen consumption reduces cardiac efficiency in diabetic mice. Diabetes. 2006;55:466-73.

43. Chatham JC, Forder JR. Relationship between cardiac function and substrate oxidation in hearts of diabetic rats. Am J Physiol. 1997;273:H52-8.

44. Chatham JC, Gao ZP, Forder JR. Impact of 1 wk of diabetes on the regulation of myocardial carbohydrate and fatty acid oxidation. Am J Physiol. 1999;277:E342-51.

45. Veiga-da-Cunha M, Gerin I, Chen YT, et al. A gene on chromosome 11q23 coding for a putative glucose - 6-phosphate translocase is mutated in glycogen-storage disease types Ib and Ic. Am J Hum Genet. 1998;63:976-83. 
46. Boztug K, Appaswamy G, Ashikov A, et al. A syndrome with congenital neutropenia and mutations in G6PC3. N Engl J Med. 2009;360:32-43.

\section{Figures}
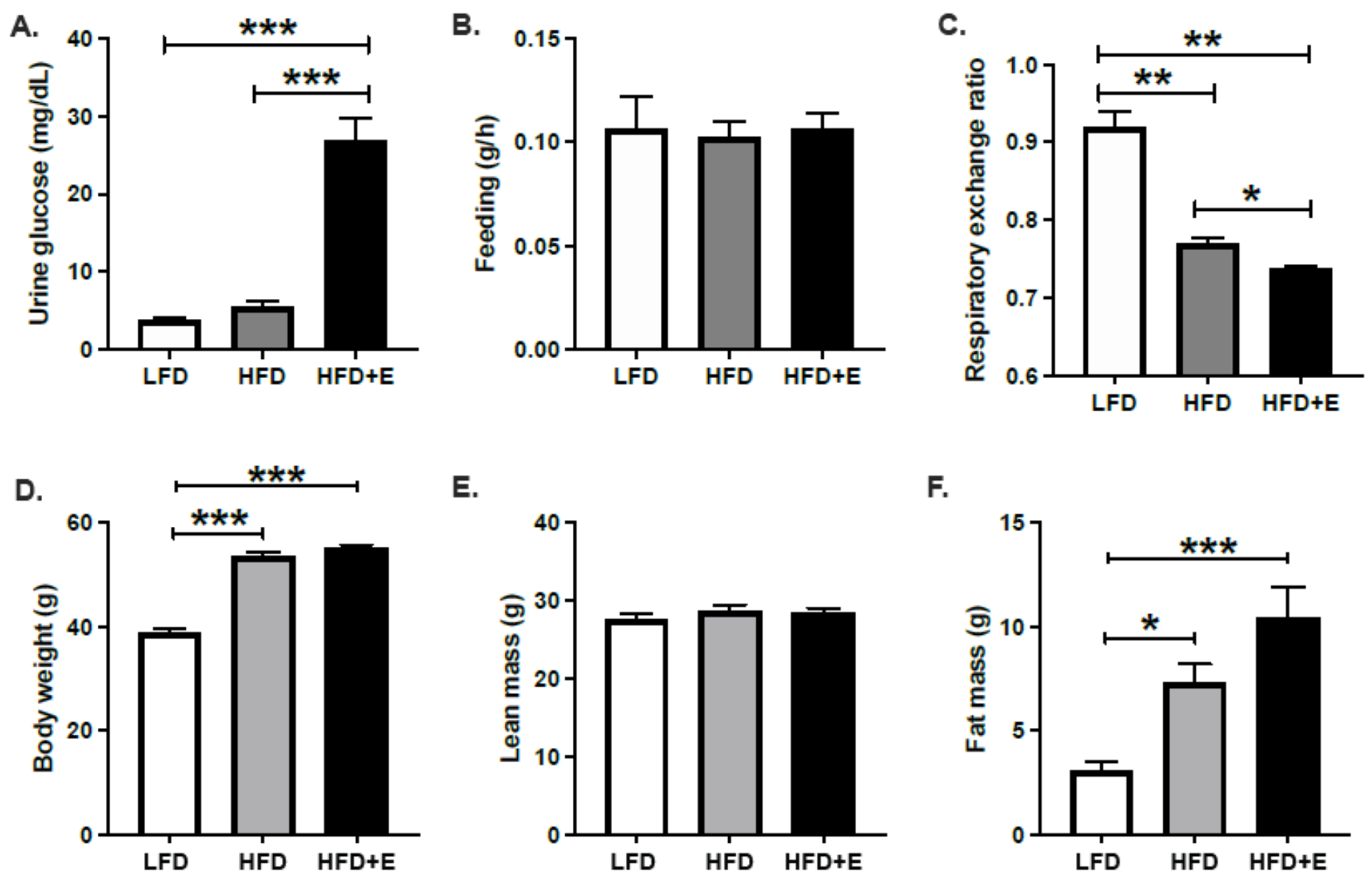

E.

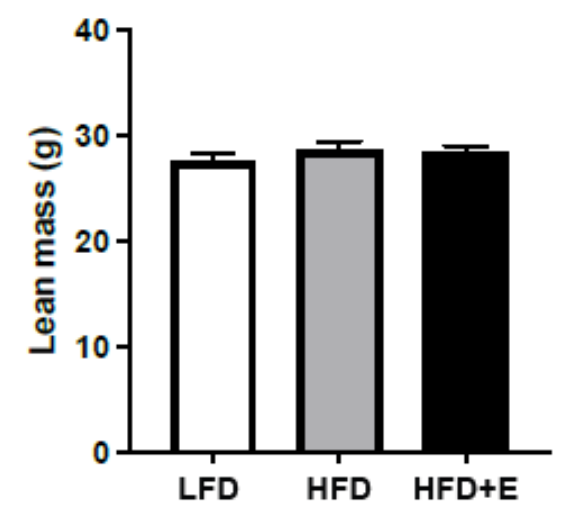

F.

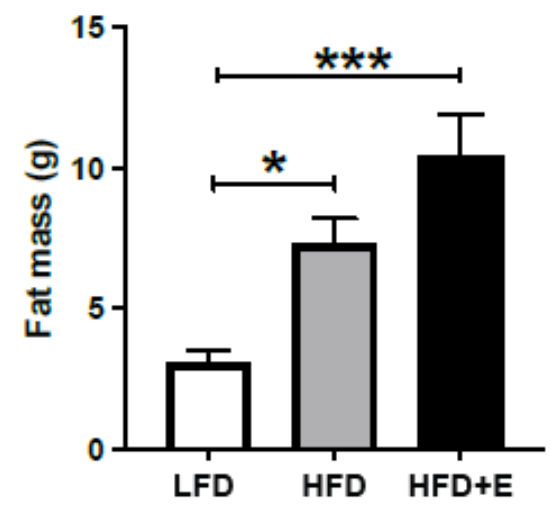

Figure 1

EMPA increases glucosuria and promotes whole-body lipid oxidation. A. Urine glucose levels measured in the morning in ad libitum fed mice after two weeks of EMPA diet. B. Feeding measured during the second week of EMPA treatment as the hourly average of 3 different days and the amount of food consumed over $24 \mathrm{~h}$. C. The $24 \mathrm{~h}$ average respiratory exchange ratio measured in metabolic cages during the second week of EMPA treatment. D. Body weights after four weeks of EMPA treatment. E-F. Lean and fat mass measured by $1 \mathrm{H}-\mathrm{NMR}$ after four weeks of EMPA treatment. Data are the mean s.e.m. for groups of $n=4-6$ for A-C and $n=15-16$ for D-F. Data were compared by one-way ANOVA and followed by multiple comparison testing to compare all groups when a significant effect was observed. ${ }^{*} P<0.05,{ }^{*} P<0.01$, $\star \star * P<0.001$. 
A.

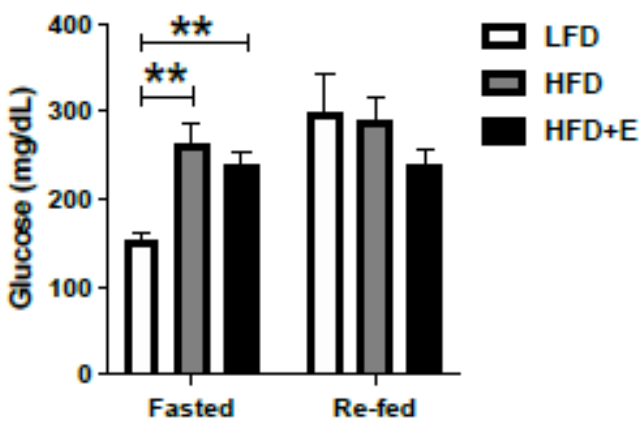

C.

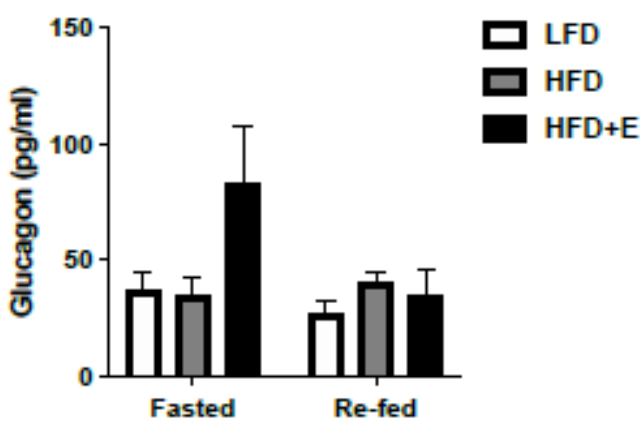

E.

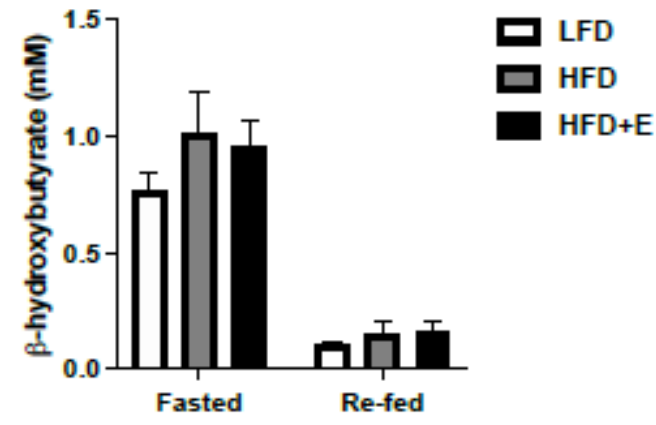

B.

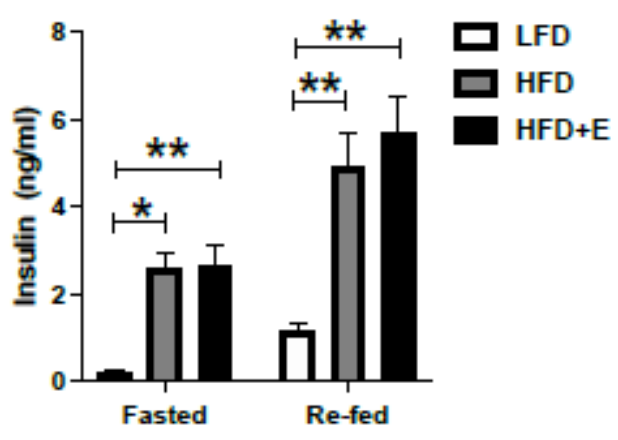

D.

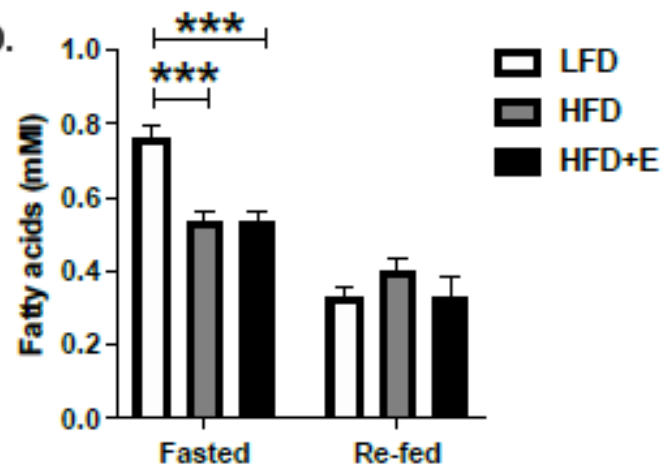

Figure 2

Plasma metabolite and hormone levels in response to fasting and re-feeding. A. Plasma glucose levels by glucose oxidase method. B. Plasma insulin levels measured by ELISA. C. Plasma glucagon levels measured by ELISA. D. Plasma fatty acids measured by spectrophotometric assay. E. Plasma Bhydroxybutyrate levels measured by spectrophotometric assay. Data are the mean + s.e.m. for groups of $\mathrm{n}=6$. Data were compared by one-way ANOVA and followed by multiple comparison testing to compare all groups when a significant effect was observed. ${ }^{\star} P<0.05,{ }^{*} \mathrm{P}<0.01,{ }^{\star} * \star P<0.001$. 

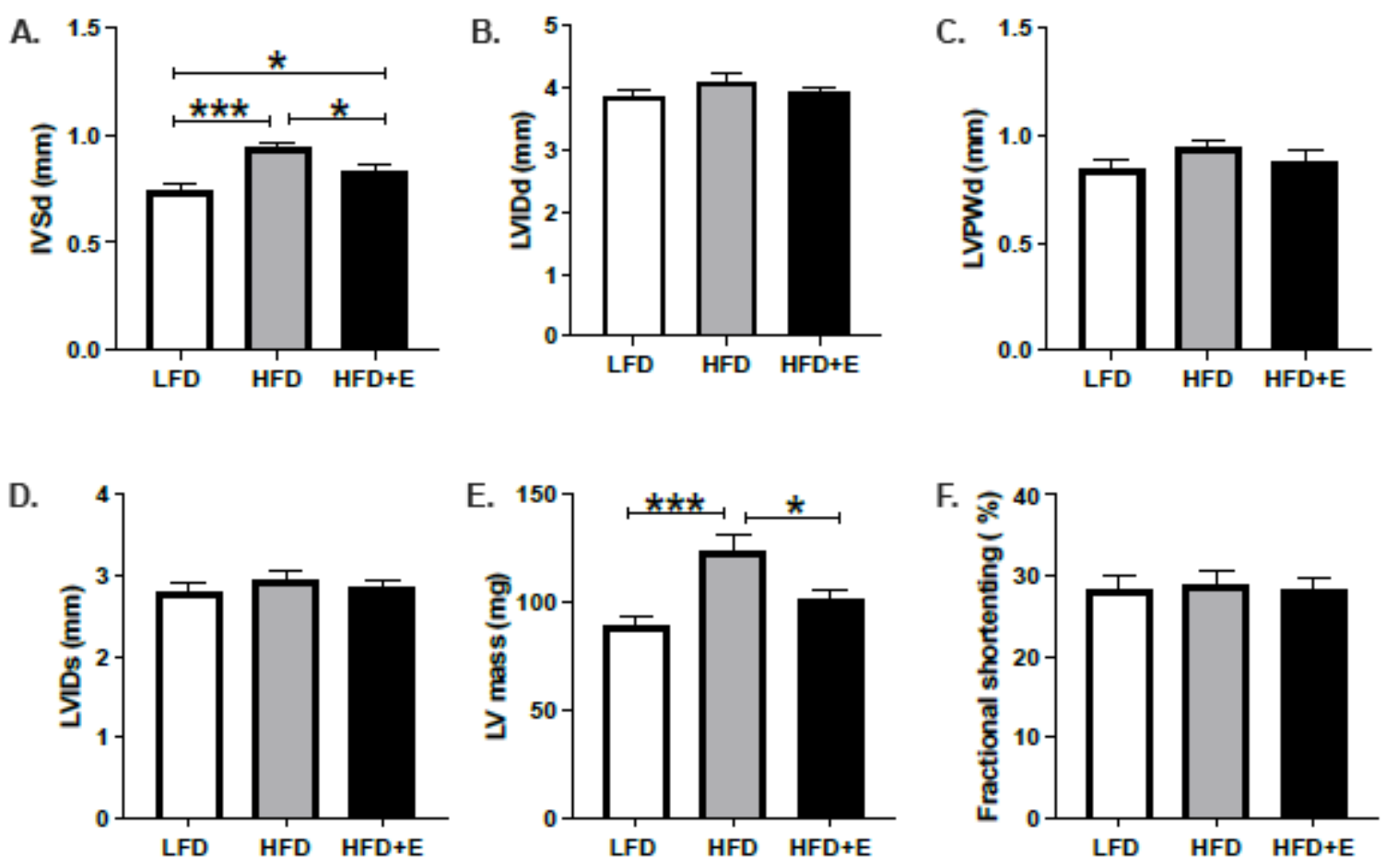

G.

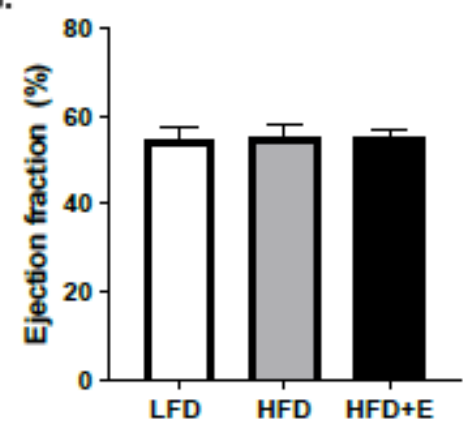

Figure 3

Cardiac hypertrophy is reduced in EMPA-treated mice. Ventricular dimensions and mass measured by echocardiography. A. Interventricular septum during diastole (IVSd). B. Left ventricular internal dimension during diastole (LVIDd). C. Left ventricular posterior wall during diastole (LVPWd). D. Interventricular septum during systole (IVSs). E. Left ventricular internal dimension during systole (LVIDs). F. Left ventricular posterior wall during systole (LVPWs). G. Estimated left ventricular mass (LV mass). $\mathrm{H}$. Fractional shortening. I. Ejection fraction. Data are the mean + s.e.m. for groups of $n=15-16$. Data were compared by one-way ANOVA and followed by multiple comparison testing to compare all groups when a significant effect was observed. ${ }^{*} \mathrm{P}<0.05,{ }^{\star}{ }^{\mathrm{P}}<0.01,{ }^{\star} * \star \mathrm{P}<0.001$. 
A.

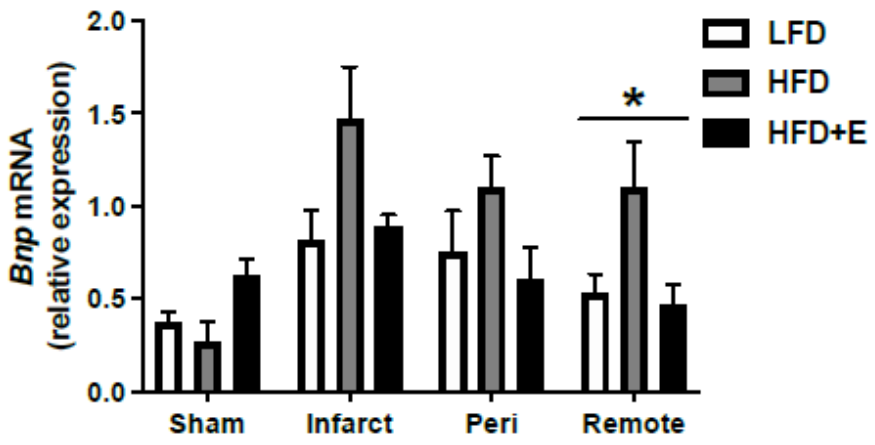

B.

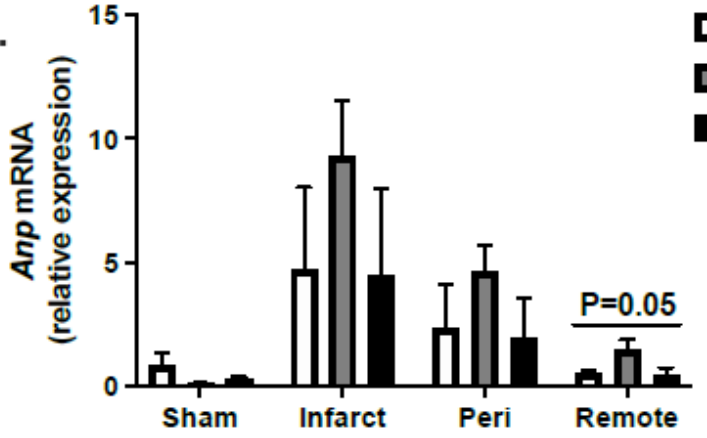

RFD

MFD

HFD+E

Figure 4

Induction Knp and Amp following coronary artery ligation is attenuated in EMPA-treated mice. A-B. Bn and Ans mRNA measured from heart samples of sham operated mice and areas of infarct, peri-infarct and remote heart of mice one week after coronary artery ligation (CAL) without reperfusion. Data are the mean + s.e.m. for groups of $n=3-4$ sham and $n=5-6$ for CAL. Data were compared by one-way ANOVA and followed by multiple comparison testing to compare all groups when a significant effect was observed. $* \mathrm{P}<0.05$.

Page 20/23 
A.
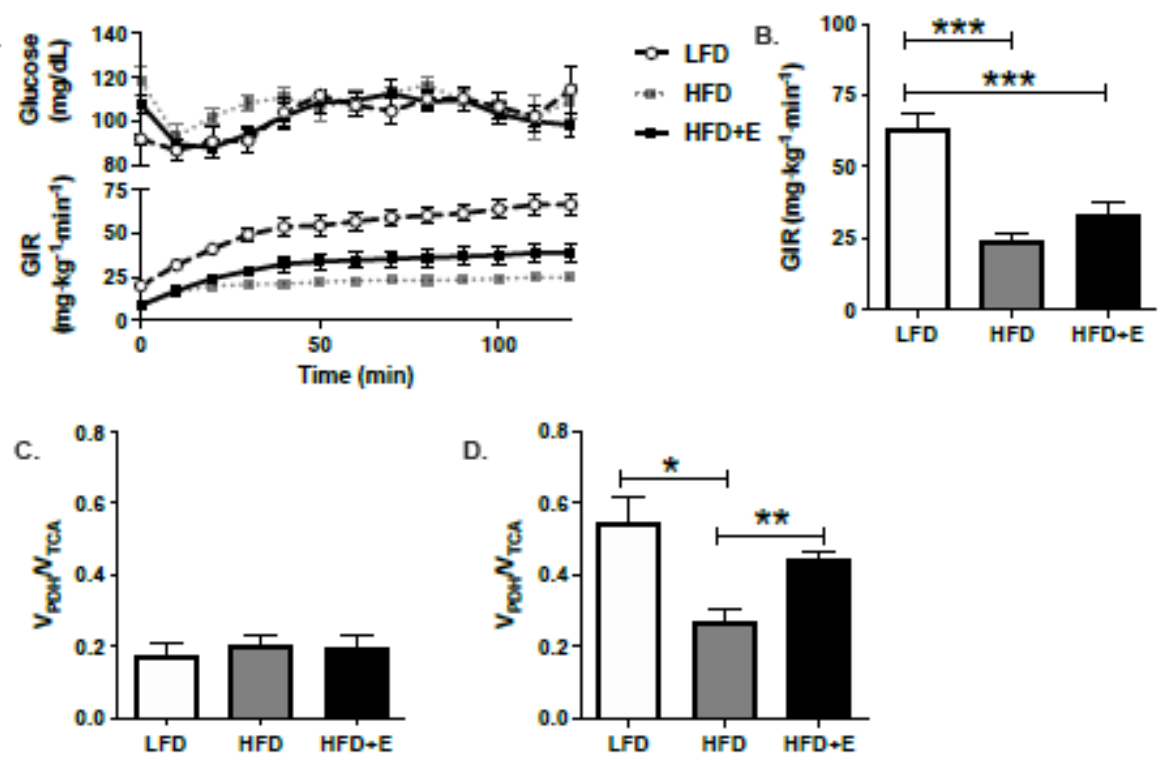

E
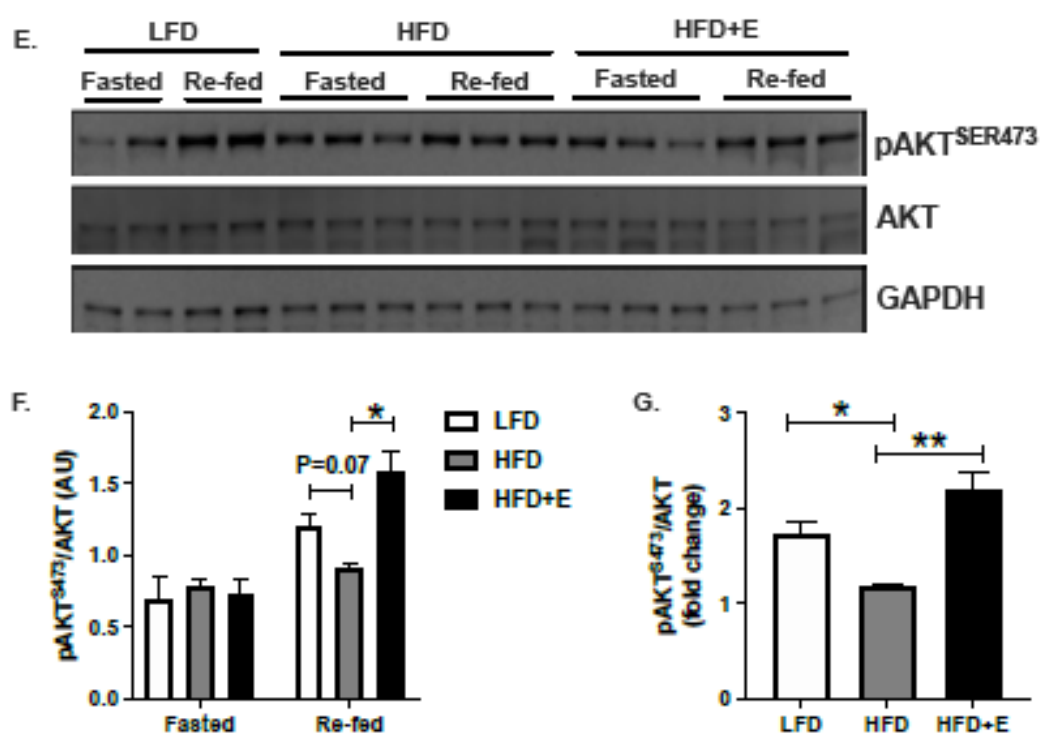

Figure 5

EMPA restores cardiac metabolic flexibility. A. Time course data for plasma glucose levels and glucose infusion rates (GIR) during hyperinsulinemic euglycemic clamps. B. GIR at steady-state or final 40 min of the infusions shown in A. C. Relative glucose oxidation to fat oxidation or VPDH/VTCA measured in heart from fasted mice. D. VPDH/VTCA measured in heart following hyperinsulinemic euglycemic clamp. E. Representative immunoblots for phosphorylated AKT at serine 473 (pAKTSER473), total AKT and GAPDH. F. Quantification of data in E. G. Fold-change in pAKT levels calculated from data in F. Data are the mean + s.e.m. for groups of $n=4-6$. Data were compared by one-way ANOVA and followed by multiple comparison testing to compare all groups when a significant effect was observed. ${ }^{*} P<0.05,{ }^{*} P<0.01$, $\star \star \star \mathrm{P}<0.001$. 

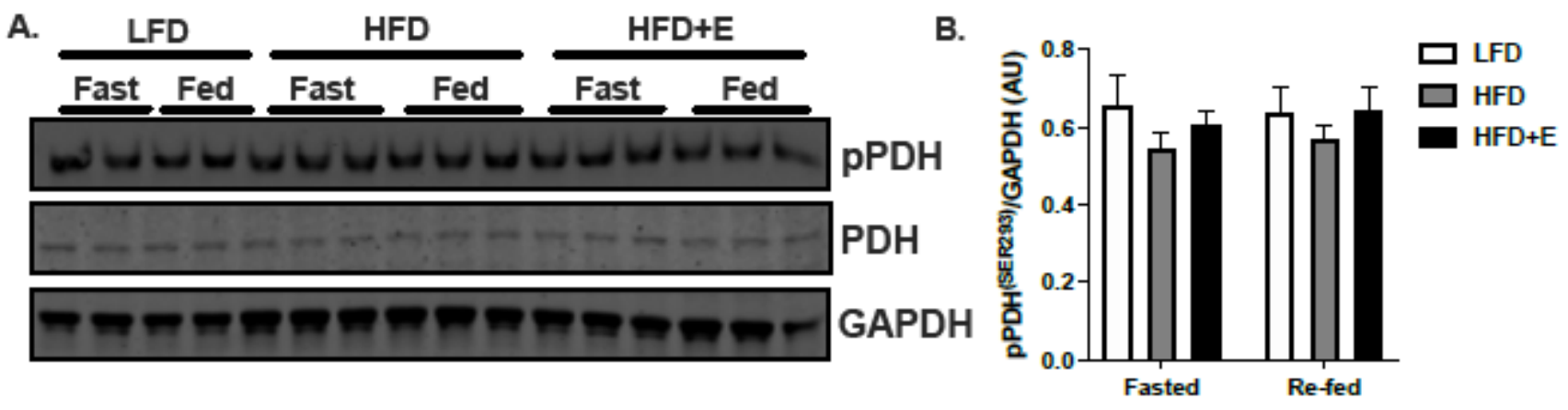

C.

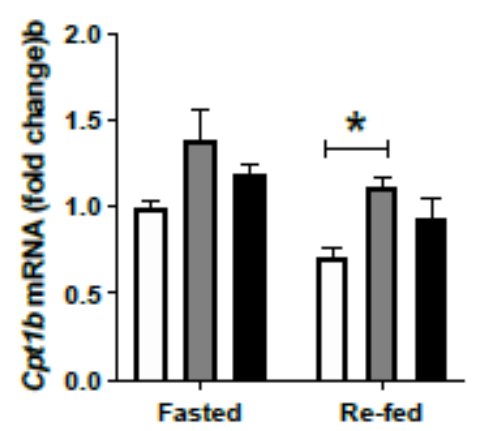

F.

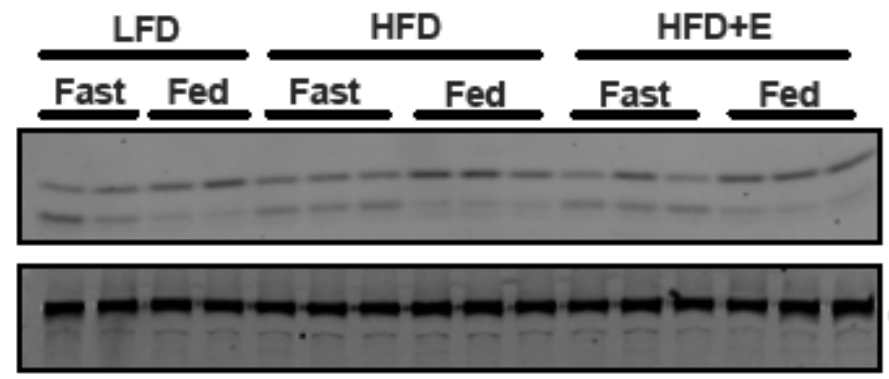

D.

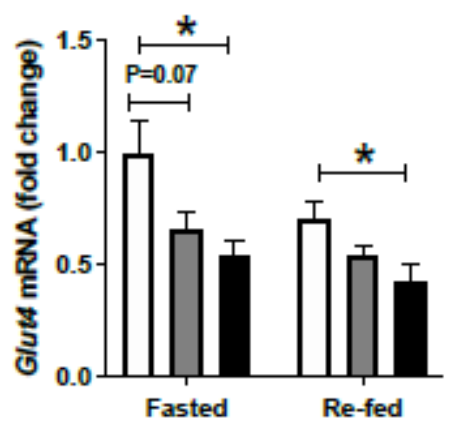

LC3

GAPDH
E.

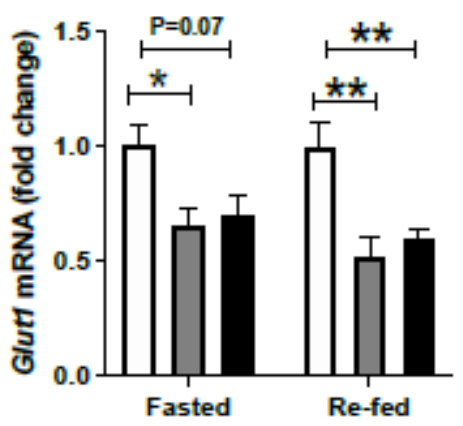

G.

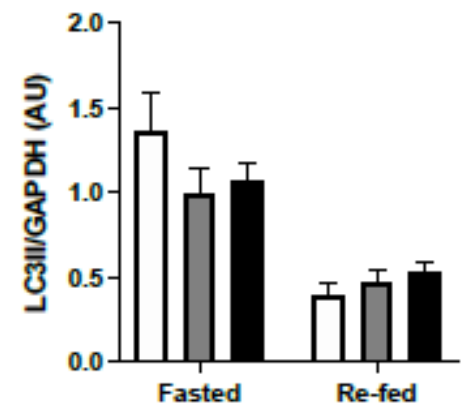

Figure 6

Changes in PDH, CPTI and autophagy do not account for changes in metabolic substrate utilization in EMPA-treated mice. A. Representative immunoblots for phosphorylated PDH at serine 293 (pPDHSER293), total PDH and GAPDH. B. Quantification of data in A. C-E. Gene expression by QPCR. F. Representative immunoblots for LC3 and GAPDH. G. Quantification of data in F. Data are the mean + s.e.m. for groups of $n=4-6$. Data were compared by one-way ANOVA and followed by multiple comparison testing to compare all groups when a significant effect was observed. ${ }^{*} P<0.05,{ }^{\star *} P<0.01$. 
A.

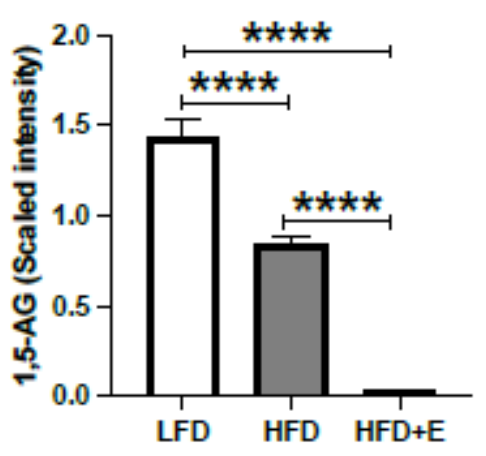

C.

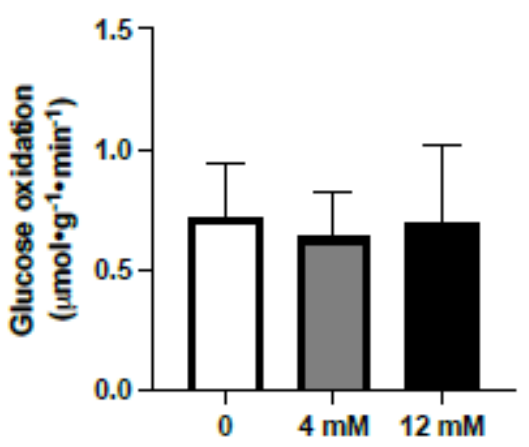

E.

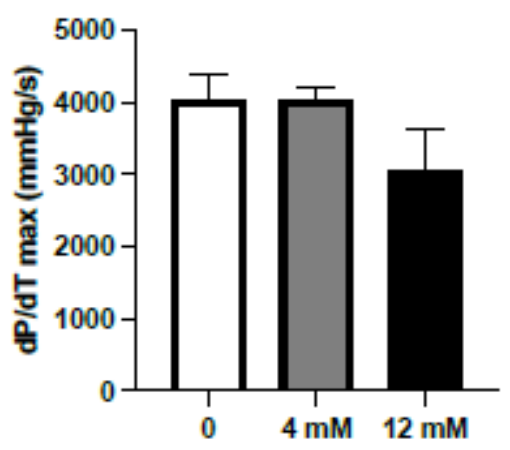

B.

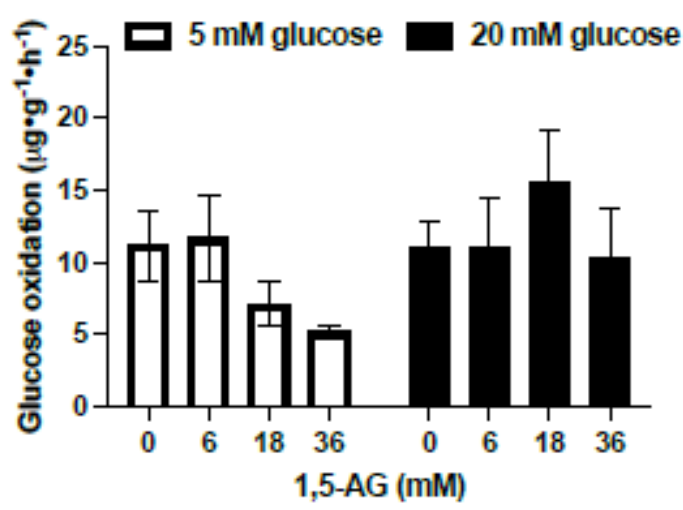

D.

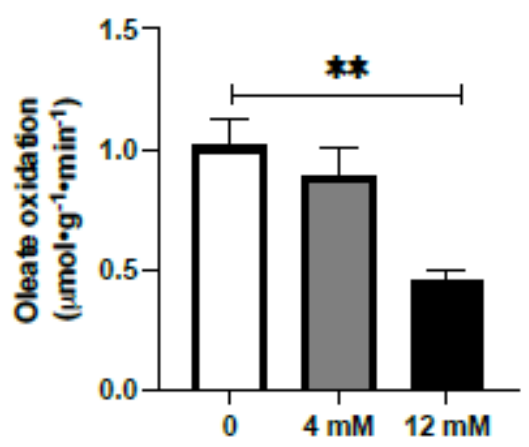

F.

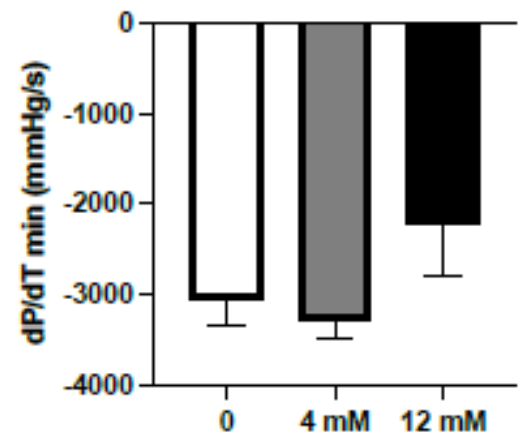

Figure 7

EMPA reduces cardiac 1,5-anhydroglucitol levels. A. Cardiac levels of 1,5-anhydroglucitol (1,5-AG) measured by LC-MS. Data are the mean + s.e.m. for groups of $n=6$. B. Rates of glucose oxidation in response to varying glucose and 1,5-AG levels in H9C2 cells. C-D. Rates of glucose and oleate oxidation in the presence of increasing 1,5-AG in ex vivo working heart system. E-F. Ventricular maximum and minimum pressure changes during working heart study. Data are the mean + s.e.m. for groups of $n=3-4$. Data were compared by one-way ANOVA and followed by multiple comparison testing to compare all groups when a significant effect was observed. ${ }^{* *} P<0.01,{ }^{* \star \star *} p<0.0001$. 